\title{
EDITORIAL
}

\section{Cannabis: the next villain on the lung cancer battlefield?}

\author{
C. Brambilla*,\# and M. Colonna*,
}

ung cancer epidemics arose and spread in western countries when the tobacco industry created the manufactured cigarette and realised that nicotine addiction was the most adaptable way to increase and secure long-term sales [1]. In spite of well-known toxicity of tobacco smoke [2] and the proven relationship of tobacco smoking with lung cancer incidence [3], the tobacco industry took advantage of the lack of response by western governments, concerning the alarms raised by physicians and citizen associations, and set up a very powerful marketing process directed at smokers, adult males and nonsmokers, females and adolescents with devastating effects. In all western countries the percentage of smokers increased, and the age at which the first cigarette was smoked decreased. Since susceptibility of females to tobacco carcinogens is higher, lung cancer in females equalled or exceeded lung cancer in males in different countries [4], even in females with a lower, but regular, cigarette consumption. The age of lung cancer occurrence followed the age that people started smoking. In the 1950s, the average ages for the first cigarette smoked and for lung cancer onset were 20-30 yrs and $\geqslant 60 \mathrm{yrs}$, respectively, but at the turn of the 20th century these were $<12$ yrs and $\geqslant 40 \mathrm{yrs}$, respectively. The electroshock was the revelation of the tobacco industry's villainies and was associated with a strong consumer pressure on the western governments, at least to ban tobacco from advertisements, schools and public housing. The most powerful action was probably the individual realisation that tobacco smoking is a killer. However, the story of tobacco epidemics is not over as the tobacco industry has focused on non-western countries, with the help of governments who were happy to receive the tax bonanza or become competitors with national production, such as in China.

Nonetheless, tobacco cessation is now gaining ground and the incidence of lung cancer has peaked in the USA. Cancer incidence first decreased in males and apparently has now also decreased in females [5] and is becoming more and more a cancer of ex-smokers. Tobacco smoking prevention, as well as early detection of lung cancer, remains the driving force of the respiratory community for the forthcoming years.

\footnotetext{
*Institut Albert Bonniot, INSERM U823, La Tronche, " Université Joseph Fourier, Grenoble, and "Isere Cancer Registry, Meylan, France.

STATEMENT OF INTEREST: None declared.

CORRESPONDENCE: M. Colonna, Isere Cancer Registry, 23 Chemin des Sources, Meylan, 38240 France. Fax: 33 476418700. E-mail: mcolonna.registre@wanadoo.fr
}

If the respiratory community wants to continue this trend in countries where tobacco regulations are enforced, should it raise the alarm against the arrival of a new villain on the lung cancer battlefield? The study by ALDINGTON et al. [6], in the present issue of the European Respiratory Journal, shows that the risk of developing lung cancer is higher in a population of cannabis smokers as compared with a population matched for associated tobacco consumption. In this population-based, case-control study, the cases are representative of the distribution of cancers according to histology, age and sex, and the quantification of the association between cannabis smoking and lung cancer is representative of situations that may be encountered in countries similar to New Zealand. In this population, the risk of lung cancer among cannabis smokers with $\geqslant 10.5$ joint-yrs of exposure was 5.7-fold higher than the risk among noncannabis smokers.

Although some may comment on the methodology of the study, the conclusions are robust; cannabis smoking increases the risk of developing a lung cancer independently of an eventual associated tobacco exposure. The study confirms preliminary conclusions [7] using a population-based, case-control study that avoids the bias of hospital-based studies. As in the tobacco story, we are now confronted with evidence and have to switch from a statistical association to the biological indication that some components of cannabis itself or cannabis smoke are real lung carcinogens, able to induce oncogenic molecular changes in the respiratory tract. The prudence principle should be sufficient to convince everybody that lung cancer has to be added to the list of secondary effects of cannabis smoking, along with asthma and chronic obstructive pulmonary disease [8-11]. Again, as in the tobacco story, the delay between smoking and death from cancer strongly attenuates an individual's perception of risk, whereas the political opinion is that cannabis consumption is lethal. It is easier to understand that driving a car under the influence of several "joints" is dangerous, particularly for the innocent individuals who may become inadvertently involved [12]. In this case, it is easy to convince politicians of the risk, but individual attitudes will probably take many years to educate [13]. The biological effects of cannabis components have been studied particularly for their psychotropic effects, and may be used to alleviate the consequences of advanced disease [14]. However, the studies on molecular alteration risk are sparse. The first report [14] was rather optimistic since the conclusions were that cannabinoids could be considered as anti-oncogenic molecules, which is true for some components of cannabis. A further study showed that, on the contrary, cannabis smoke and some main components of 
cannabis smoke clearly induce oncogenic changes in cell lines, as well as in bronchial biopsies [15]. The case-control study by ALDINGTON et al. [6] provides a quantification of the effect of cannabis smoking: the increased risk for each joint-yr of cannabis smoking was similar to that for each pack-yr of cigarettes. In other words, the risk of lung cancer increased by $8 \%$ for each joint-yr of cannabis exposure after adjustment for confounding variables, including tobacco smoking.

We have the epidemiological association and the biological clue, but is this a societal or a minority problem? To be clear, is there a risk of spreading from a leisure occupation in a restricted part of society to a regular generalised consumption particularly in youngsters, reproducing the tobacco epidemics of the 20th century? Epidemiologists present alarming data on this point [16] showing that the use of cannabis has to be considered as a societal problem.

It would surely be interesting to find out the percentage of readers of our editorial who have been confronted by the fact that their children or their friends' children are cannabis smokers or have been approached by cannabis dealers. We are not facing the big tobacco companies with their huge amount of legal money, but an even more vicious underground enemy.

The conclusion of our editorial is that yes, cannabis is dangerous. We have to alert our authorities and, more practically, to ask in our every day practice "do you smoke tobacco and/or cannabis?" in order to systematically provide minimal council to our patients, friends and children.

\section{REFERENCES}

1 McCaffree DR. The "Big Tobacco" settlement: the ACCP viewpoint. American College of Chest Physicians. Chest 1998; 113: 1682-1683.

2 United States Department of Health and Human Services. The Health Consequences of Smoking. Cancer: A Report of the Surgeon General. Rockville, MD, United States, 1982. http://usdhhs.gov
3 Royal College of Physicians. Smoking and Health Now. London, Pitman Medical, 1971.

4 Brennan P, Bray I. Recent trends and future directions for lung cancer mortality in Europe. Br J Cancer 2002; 87: 43-48.

5 Jemal A, Siegel R, Ward E, Murray T, Xu J, Thun MJ. Cancer statistics, 2007. CA Cancer J Clin 2007; 57: 43-66.

6 Aldington S, Harwood M, Cox B, et al. Cannabis use and risk of lung cancer: a case-control study. Eur Respir J 2008; 31: 280-286.

7 Mehra R, Moore BA, Crothers K, Fiellin DA. The association between marijuana smoking and lung cancer: a systematic review. Arch Intern Med 2006; 166: 1359-1367.

8 Voirin N, Berthillier J, Benham-Luzon V, et al. Risk of lung cancer and past use of cannabis in Tunisia. J Thorac Oncol 2006; 1: 577-579.

9 Melamed R. Cannabis and tobacco smoke are not equally carcinogenic. Harm Reduct J 2005; 18: 2-21.

10 Tashkin DP. Smoked marijuana as a cause of lung injury. Monaldi Arch Chest Dis 2005; 63: 93-100.

11 Kalant H. Adverse effects of cannabis on health: an update of the literature since 1996. Prog Neuropsychopharmacol Biol Psychiatry 2004; 28: 849-863.

12 Ramaekers JG, Berghaus G, Van Laar M, Drummer OH. Dose related risk of motor vehicle crashes after cannabis use. Drug Alcohol Depend 2004; 73: 109-119.

13 Begg DJ, LangleY JD, Stephenson S. Identifying factors that predict persistent driving after drinking, unsafe driving after drinking, and driving after using cannabis among young adults. Accid Anal Prev 2003; 35: 669-675.

14 Smith PF. Cannabinoids in the treatment of pain and spasticity in multiple sclerosis. Curr Opin Investig Drugs 2002; 3: 859-864.

15 Carchman RA, Harris LS, Munson AE. The inhibition of DNA synthesis by cannabinoids. Cancer Res 1976; 36: 95-100.

16 Tashkin DP, Baldwin GC, Sarafian T, Dubinett S, Roth MD. Respiratory and immunologic consequences of marijuana smoking. J Clin Pharmacol 2002; 42: Suppl. 11, 71S-81S. 